\title{
PERCEPÇÃO DE MORADORES DE COMUNIDADES RURAIS SOBRE MUDANÇAS NA PAISAGEM NO SEMIÁRIDO POTIGUAR
}

\author{
J. A. ARAÚJO* e R. F. SOUZA \\ Doutora em Desenvolvimento e Meio Ambiente \\ azevedo.jane2@yahoo.com.br
}

Artigo submetido em 23 x/02/2015 e aceito em 07/11/2016

DOI: $10.15628 /$ holos.2016.2792

\section{RESUMO}

O estudo objetivou registrar mudanças ocorridas no meio rural das comunidades Almas, Domingas, Sussuarana II e Colonos, adjacentes ao rio Seridó, identificando os processos de mudança na paisagem local e analisando as possíveis alterações ambientais sob a ótica dos participantes da pesquisa nas comunidades estudadas. Foram feitas entrevistas com moradores que residiam há mais de vinte anos nos locais. Setenta por cento dos entrevistados perceberam mudanças na paisagem, tendo sido relatadas alterações na vegetação, nas pastagens, na água e no solo.

PALAVRAS-CHAVE: Parelhas; Rio Seridó; Alterações Ambientais; Recursos Naturais.

\section{PERCEPTION OF RESIDENTS OF RURAL COMMUNITIES ABOUT MODIFICATIONS IN THE LANDSCAPE OF THE POTIGUAR SEMIARID}

\section{ABSTRACT}

This study aimed to investigate modifications in the rural environment of the communities of Almas, Domingas, Sussuarana II and Colonos, all of them adjacent to the Seridó River, identifying the processes of changes in the local landscape and analyzing the environmental modifications from the perspective of research participants in the studied communities. Interviews were conducted with residents who lived for more than twenty years in these locations. Seventy per cent of the participants noticed changes in the landscape, including the vegetation, pastures, water and soil.

KEYWORDS: Parelhas; Seridó River; Environmental Modifications; Natural Resources. 


\section{INTRODUÇÃO}

As relações que os seres humanos estabelecem com os locais nos quais habitam constroem a história de cada indivíduo. Por meio disso, são instituídos alguns vínculos que permitem a estes perceberem o meio ambiente através das vivências cotidianas. Os processos que envolvem a relação do homem com o meio em que vive são complexos por revelarem posse de um espaço físico, em constante transformação, que envolve aspectos sobre a qualidade ambiental e de vida.

Nesse sentindo, o ser humano insere no espaço em que ocupa características próprias, resultando em alterações físicas historicamente estabelecidas pelas suas formas de trabalho, refletindo a sua identidade no local e produzindo a transformação da paisagem, já que "a atividade humana geralmente está associada de forma direta com as unidades locais da paisagem, servindo de base para a exploração dos recursos como meio de subsistência para as atividades da população" (RODRIGUEZ; SILVA; CAVALCANTI, 2007, p. 83).

A transformação do espaço vivido pressupõe as necessidades imediatas de sobrevivência do homem. A maneira como o indivíduo vê, pensa e sente o ambiente revela o modo como ele utiliza os recursos naturais. De acordo com COSGROVE (1998, p. 98), "a paisagem, de fato, é uma 'maneira de ver', uma maneira de compor e harmonizar o mundo externo em uma 'cena', em uma unidade visual". E ainda,

A paisagem está intimamente ligada a uma nova maneira de ver o mundo como uma criação racionalmente ordenada, designada e harmoniosa, cuja estrutura e mecanismo são acessíveis à mente humana, assim como o olho, e agem como guias para os seres humanos em suas ações de alterar e aperfeiçoar o meio ambiente (COSGROVE, 1998, p. 98).

Desse modo, as atividades humanas alteram sobremaneira os ecossistemas. No semiárido brasileiro, por exemplo, o uso dos recursos naturais da Caatinga é intenso. A exploração desses recursos apresenta aspectos distintos de acordo com a percepção ambiental de cada indivíduo, considerando que "se a realidade é apenas uma, cada pessoa a vê de forma diferenciada" (SANTOS, 1997, p. 62).

Isto resulta na exploração contínua dos recursos naturais, que são essenciais para a subsistência humana. O modo como o indivíduo explora o meio em que vive ocasiona, ao longo do tempo, mudanças no clima, na vegetação, no solo, na paisagem, ou ainda mudanças de pensamento, valores e significados a respeito do ambiente onde se habita. Todavia,

“(...) presume-se que seja possível contribuir para uma relação mais harmoniosa entre o homem e a natureza, inferindo considerações e elaborando estratégias para a preservação e a melhoria da qualidade ambiental e de vida das pessoas" (SANTOS et al., 2004). 
Quanto mais se explora um referido lugar mais se conhece e se constroem novas relações de interação homem/natureza. De acordo com Rodriguez; Silva; Cavalcanti, (2007, p. 155),

(...) os seres humanos e a natureza unem-se como um todo integral no trabalho e na organização social. O intercâmbio de energia, matéria e informação, que se utiliza principalmente mediante a atividade produtiva, é condição necessária para a existência da sociedade.

Assim, a sociedade caracteriza os processos históricos de um lugar ou de uma região através da ocupação e apropriação de espaços. Um exemplo disso são as sociedades que se desenvolveram nas proximidades de cursos d'água, locais propícios ao fornecimento de alimento e água.

Na região do Seridó, localizada na porção centro-sul do estado do Rio Grande do Norte, alguns municípios surgiram no entorno de corpos d'água. O rio Seridó, importante afluente da Bacia Hidrográfica do Piranhas-açu, abriga no seu curso populações que utilizam as suas margens para uma série de atividades.

A cidade de Parelhas/RN se desenvolveu nas cercanias do rio Seridó. O espaço onde corre o rio, nesse município, abriga comunidades rurais, além de passar pela sede municipal. À jusante da sede municipal estão localizadas quatro comunidades rurais que utilizam o rio direta e/ou indiretamente para o fornecimento de água (para consumo humano e animal), para a produção agrícola de subsistência ou para a geração de renda familiar. Essas práticas bem como o processo de ocupação dessas áreas causaram mudanças no local no âmbito social e ambiental. No que diz respeito à sua organização social, existem Associações Comunitárias que reivindicam melhorias. Outrossim, o ambiente mudou, pelo crescimento das comunidades, modificações na vegetação e consequentemente, modificações na paisagem.

Esta pesquisa objetivou registrar mudanças ocorridas no meio rural das comunidades Almas, Domingas, Sussuarana II e Colonos, adjacentes ao rio Seridó, identificando os processos de mudança na paisagem local e analisando as possíveis alterações ambientais sob a ótica dos participantes da pesquisa nas comunidades estudadas. As entrevistas e os relatos orais revelaram o cotidiano dos entrevistados e as opiniões a respeito do ambiente que os cerca, possibilitando a obtenção de detalhes concernentes ao levantamento dos aspectos de mudanças da paisagem local.

\subsection{Caracterização e localização da área de estudo}

A área do estudo localiza-se no município de Parelhas/RN situado na Microrregião do Seridó Oriental, distante $240 \mathrm{~km}$ da capital Natal. A população compreende 20.354 habitantes, 
sendo 17.084 pessoas residentes na zona urbana e 3.270 pessoas residentes na zona rural (IBGE, 2010). Esta última constitui uma "população rural residente de 16,1\%" (IBGE, 2010). A Caatinga é a vegetação predominante, o clima é semiárido, os solos são pedregosos, litólicos eutróficos e bruno não cálcico (NUNES, 2006).

A área da pesquisa abrangeu um trecho do rio Seridó, importante rio perenizado pela Barragem Boqueirão, que passa pela sede municipal. Às suas margens estão as comunidades rurais estudadas: Almas, Domingas, Sussuarana II e Colonos (Figura 1).

O rio Seridó é um importante afluente da Bacia Hidrográfica do Piranhas-Açu e seu curso se estende pelos atuais territórios da Paraíba e do Rio Grande do Norte, (...) adentrando pelo município de Parelhas, sendo suas águas represadas pela Barragem Boqueirão (MORAIS, 2005, p.24).

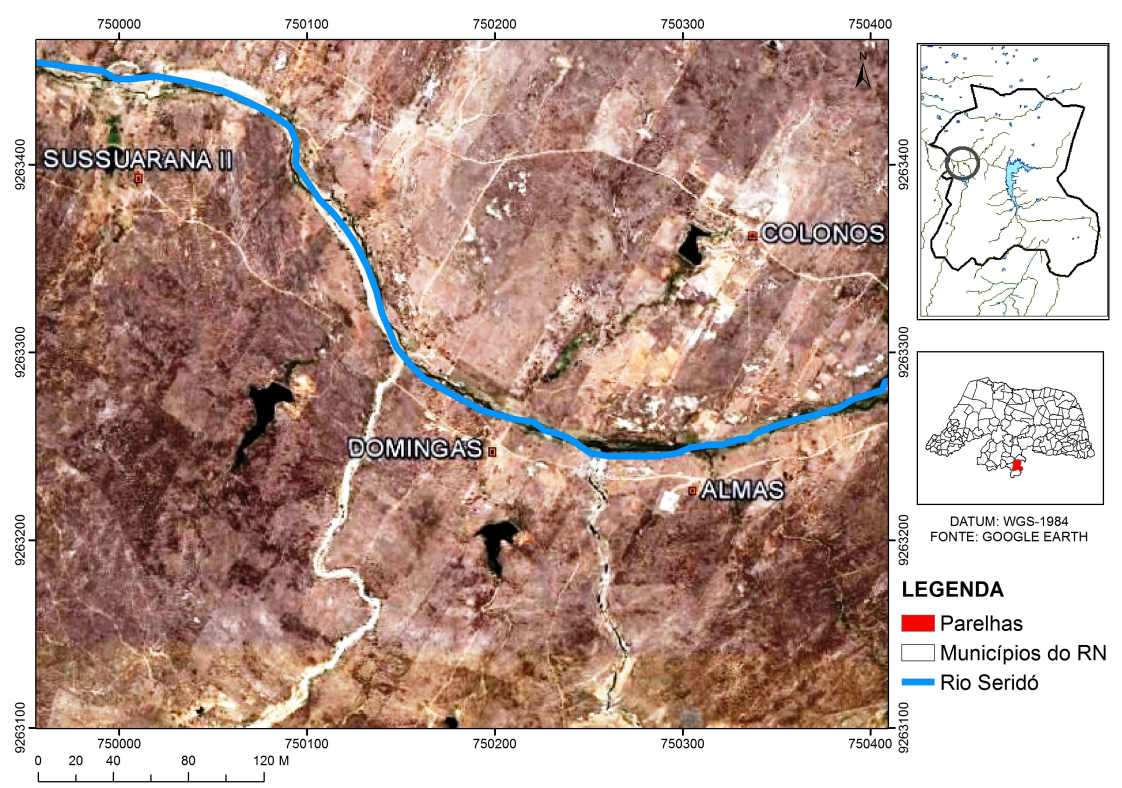

Figura 1: Localização da área de estudo. Fonte: Oliveira, 2015.

\section{METODOLOGIA}

O instrumento de coleta para obtenção dos dados foram questionários com perguntas fechadas de múltiplas escolhas e abertas, baseado nos princípios da pesquisa em Percepção Ambiental (TUAN, 1980). Foram aplicados 23 questionários com os moradores, chefes de famílias (homem ou mulher), que residem nas comunidades estudadas há 20 anos ou mais.

Foi considerado esse número de entrevistas por comunidade em função do recorte temporal de 20 anos de residência no local estabelecido para os participantes da pesquisa. $\mathrm{Na}$ comunidade Almas, Domingas, Sussuarana II e Colonos foram realizadas uma, duas, dez e dez entrevistas, respectivamente, totalizando vinte e três. Os demais moradores mudam 
constantemente de lugar - das comunidades rurais para cidade e/ou para outras comunidades, não permanecendo por muito tempo em uma mesma localidade. As entrevistas foram realizadas na residência de cada participante.

Quanto à classificação, e apoiada em Gil (2002), a pesquisa possui um caráter exploratório e qualitativo, possibilitando a consideração dos mais variados aspectos relativos ao fato estudado. Para o autor pode-se dizer que estas pesquisas têm como objetivo principal o aprimoramento de ideias ou a descoberta de intuições.

\section{RESULTADOS E DISCUSSÃO}

O gênero dos entrevistados nas quatro comunidades rurais correspondeu a $26 \%$ feminino e 74\% masculino. A faixa etária da maioria dos entrevistados correspondeu a idades de 45 a 59 anos e 60 anos ou mais (39\% e 39\% respectivamente), 13\% de 35 a 44 anos e $9 \%$ estão na faixa etária de 25 a 34 anos. O local de origem da maioria dos entrevistados é a zona urbana do município. A maioria reside no local de 20 a 30 anos.

Os entrevistados, em sua maioria, têm Ensino Fundamental Incompleto (70\%) e apenas 6\% concluíram o Ensino Médio. Os respondentes que nunca foram à escola corresponderam a 18\%; vale salientar que apesar de afirmarem nunca ter ido à escola, estes sabem assinar seu nome completo.

No que diz respeito à quantidade de pessoas que compõem a família, destacam-se as que são compostas por três a quatro pessoas com 44\%, as que têm acima de quatro pessoas com 39\%, e as compostas de duas pessoas corresponderam a $17 \%$. As famílias que apresentam composições mais numerosas são comuns em zonas rurais, fato que pode estar relacionado à maior necessidade de mão de obra no trabalho do campo.

Estar próximo ao rio proporciona a essas comunidades a garantia de terem água para realizar suas atividades rurais e domésticas. A água pode vir do rio, que é perenizado pela Barragem Boqueirão, bem como de cisternas de captação de água de chuva do Projeto "Um milhão de Cisternas" (P1MC), do Governo Federal. Considerando que água no semiárido é um fator limitante para a sobrevivência e bem-estar, os moradores que se encontram nas adjacências do rio sentem-se privilegiados, conforme expressaram nas entrevistas. A água do rio é usada para irrigação, consumo humano e animal.

As pessoas que mais perceberam mudanças ocorridas nas suas comunidades foram aquelas com maior tempo de moradia e idade, pois o tempo de residência e de vivência maior nas comunidades confere aos moradores mais antigos um conhecimento diferenciado da realidade que os cerca.

Quando foram perguntados se houve alguma mudança na paisagem local $70 \%$ dos entrevistados responderam sim, e 30\% responderam que não houve mudança. 
Nesse sentido, o entrevistado da comunidade Domingas percebeu que a paisagem da comunidade mudou, pois, a vegetação está diferente; pode-se dizer que hoje já não tem a diversidade de plantas nativas na comunidade que existia há 20 anos.

Na comunidade Sussuarana II houve relatos de que há 20 anos, às margens do rio Seridó, havia Coqueiro (Cocos nucifera L.), Mangueira (Mangifera indica L.) e Oiticica (Licania rigida Benth.), enquanto que hoje há predominância de capim. Atualmente a plantação de capim é significativa no curso do rio. A paisagem, que se via antes com árvores frutíferas de médio e grande porte, foi substituída pela que se vê hoje constituída de capim. Conforme enfatiza (SANTOS, 1997, p. 66) “a paisagem não se cria de uma só vez, mas por acréscimos e substituições (...). Uma paisagem é uma escrita sobre a outra".

Alguns dos relatos dos entrevistados que perceberam mudanças na paisagem estão apresentados na tabela de contingência a seguir.

Tabela 1: Relatos dos moradores entrevistados sobre mudança na paisagem local

\begin{tabular}{l|c}
\hline \multicolumn{2}{c}{ Houve alguma mudança na paisagem nos últimos 20 anos? } \\
\hline COMUNIDADES & RELATOS \\
\hline Domingas & "Sim, a vegetação mudou." \\
Sussuarana II & "Sim, hoje só tem capim no rio." \\
Colonos & "Sim, a comunidade cresceu"; "tem \\
& $\begin{array}{r}\text { mais casas"; "devastou mais para construir } \\
\text { casas"; "a vegetação mudou." }\end{array}$ \\
\hline
\end{tabular}

Fonte: Elaborado pelas autoras, 2015.

Outra mudança constatada na paisagem local foi a quantidade de novas residências, pois os entrevistados relatam que "está mais habitado" ou que "têm mais moradores". Essa mudança pode estar relacionada com a permanência dos filhos dos moradores na comunidade. Após o casamento, estes constroem suas residências e constituem família. Assim, na comunidade Colonos os entrevistados perceberam que mudanças na paisagem tem relação com o crescimento da comunidade e com mudanças na vegetação.

Relatou-se ainda que "a água do rio é pouca, antes dava pra vê de longe". Todavia, isso ocorreu por que após a conclusão da construção da Barragem Boqueirão, na segunda metade da década de 80, o rio Seridó passou a ser perenizado. Usualmente as comportas da Barragem são abertas em fluxo contínuo para que as populações que residem às suas margens sejam beneficiadas. Porém, não quer dizer que a vazão da comporta seja similar a uma cheia como acontecia em período chuvoso antes do rio ser perenizado. Atualmente as comportas estão fechadas em função da estiagem que se prolonga desde o ano de 2011. 
Segundo relatos de alguns moradores, aconteciam grandes cheias no rio Seridó, no período chuvoso, e o seu curso permanecia com água em volume suficiente para permitir sua visualização a uma longa distância. Outrossim, devido à plantação de capim e alguns barramentos (feitos por proprietários de terra no rio para reter a água em prol de seu benefício), a água escoa com dificuldade e, entre o capim, foge à vista de quem a olha ao longe. Relatou-se também que "onde era o campo de algodão, hoje só tem jurema-preta".

A região do Seridó passou por momentos de ascensão econômica com a cotonicultura no final do século XIX. O município de Parelhas produziu algodão de excelente qualidade, sendo que muitos hectares de terra eram destinados à sua produção. A comunidade Sussuarana II também foi berço dessa monocultura, que inclusive causou danos "sobre o ambiente, a despeito dos benefícios socioeconômicos que acarretaram” (MMA, 2005, p. 55).

A atividade causou a exaustão do solo, e é possível notar as áreas degradadas na margem direita do rio em função da monocultura do algodão; algumas destas áreas apresentam indícios de recuperação, razão pela qual há presença de jurema-preta. De acordo com Maia, 2004, p. 81,

A recuperação natural de uma área devastada ocorre em várias fases, o que é chamado de sucessão natural. Em cada fase atuam as plantas e animais especializados em lidar com a situação especial de solo e clima. Por exemplo, numa área totalmente despida de vegetação, dependendo do solo e outros fatores, aparecerão plantas chamadas de pioneiras, que suportam as condições extremas de uma área sem proteção vegetal e cumprem a finalidade de cobrir o solo e começar a recuperar sua vida e fertilidade.

Desse modo, a paisagem é reveladora do presente e "uma herança de muitos momentos já passados" (SANTOS, 1997, p. 66). A percepção das mudanças na paisagem local é mais evidente para aqueles que moram há mais tempo no local e de maior faixa etária, pois outrora vivenciaram momentos de transformações sociais, ambientais e econômicas locais e regionais. Pode-se complementar com Soares, 2002, p. 105-106, que:

O estudo da paisagem passa pela concepção do que é visível, de como cada indivíduo, comunidade ou sociedade percebe e se identifica com o cenário que se vislumbra. [...] Essa paisagem, não só visualizada, percebida e sentida, é sobretudo delimitada, vive em constante transformação, uma vez que suas mudanças estão atreladas às alterações da natureza, mas sobretudo da sociedade. Daí, ao observar uma determinada área, visualiza-se o arranjo espacial do hoje, mas ao mesmo tempo, nos remetemos ao passado, quando paramos para analisar que por trás daquela paisagem há uma história, que a faz parar no tempo ou ser palco de sucessivas mudanças, conforme as atividades econômicas e culturais determinantes na origem e formação desta sociedade.

Trinta e nove por cento dos entrevistados percebeu mudanças ocorridas na água do rio Seridó, tanto em qualidade como em quantidade. Na comunidade Domingas os entrevistados disseram que a água do rio "está mais salobra e suja". Em Sussuarana II os entrevistados 
observaram que, "está ruim devido os esgotos", "antes da construção da Barragem Boqueirão era limpa", "o capim deixa a água suja", "está poluída". Na comunidade Colonos os entrevistados perceberam que a água do rio "está mais salgada" e que "está diminuindo".

Esses relatos podem estar relacionados com as atividades desenvolvidas no curso do rio. A plantação de capim, por exemplo, é basicamente feita dentro do canal ativo do rio, impedindo o fluxo normal da água e conferindo a esta uma maior turbidez, e consequentemente um aspecto "sujo"; daí os relatos de que "o capim suja a água".

A respeito de alterações na vegetação a maioria dos entrevistados disse que houve mudanças nas espécies vegetais uma vez que algumas estão diminuindo. O percentual das respostas sobre mudanças na vegetação foi de $83 \%$ para sim e $17 \%$ para não. Os entrevistados citaram algumas espécies vegetais que diminuíram: Angico (Anadenanthera macrocarpa Benth.), Caibeira (Tabebuia caraiba Mart. Bureau), Imburana (Commiphora leptophloeos Mart.), Favela (Cnidoscolus quercifolius Pohl), Jurema-preta (Mimosa tenuiflora Willd. Poir.), Mangueira (Mangifera indica L.) e Oiticica (Licania rigida Benth.).

Os entrevistados de duas comunidades perceberam mudanças no solo (30\%). $\mathrm{Na}$ comunidade Sussuarana II os entrevistados enfatizam que "a terra está desgastada e mais seca", "tem que adubar bem para produzir". Os relatos da comunidade Colonos foram similares aos de Sussuarana II, sendo também citado que "aparecem mais pragas nas lavouras".

Nas pastagens, $65 \%$ dos entrevistados perceberam mudanças, 31\% não as perceberam e $4 \%$ não souberam informar. Na comunidade Domingas foi relatado que "o pasto está fraco e diminuiu ano após ano". Na comunidade Sussuarana II, as mudanças que foram percebidas dizem respeito à melhoria de pasto: "tem mais pasto para os rebanhos", mas "quando não chove bem o pasto diminuiu". Na comunidade Colonos os entrevistados relataram também que o pasto está diminuindo.

Por ser a paisagem uma "interface da natureza com a sociedade" (RODRIGUEZ; SILVA, 2002, P. 98), os moradores perceberam mudanças nos seus constituintes, como por exemplo, na água, solo, vegetação e pastagens.

\section{CONCLUSÃO}

As mudanças ocorridas na paisagem foram percebidas por $70 \%$ dos entrevistados, os quais ainda apontaram que as mudanças mais expressivas são percebidas na vegetação, nas pastagens, no solo e na água.

As pessoas que perceberam as mudanças na paisagem moram na comunidade há mais tempo e têm faixa etária maior, ou seja, idades e entre 45 e 60 anos ou mais. Estes identificam com mais facilidade as alterações na fisionomia do local, retratando-o como era anteriormente e como ele hoje se apresenta. 
A paisagem na qual estão inseridas as comunidades rurais estudadas, de fato, mudou. Ocorreram modificações através de atividades desenvolvidas pelos residentes ao longo dos anos, as quais incluem práticas de agricultura, pecuária, plantio de capim e a cotonicultura. Embora a percepção acerca dessas transformações inclua outras concernentes ao número de moradores que aumentou nos últimos anos, bem como o número de residências, esta percepção também abrange mudanças ambientais, da degradação do solo até a fase inicial de recuperação de áreas degradadas pela cotonicultura - sucessão natural.

São processos históricos de mudanças na paisagem que corroboram o relacionamento dos moradores com os recursos naturais disponíveis. O desenvolvimento das suas atividades cotidianas de pecuária, agricultura, plantação de capim, entre outras, providenciam o sustento dessas populações, evidenciando as trocas decorrentes do relacionamento homem-natureza, que configuraram ao longo dos anos e ainda configuram nos dias atuais, o cenário semiárido onde estão situadas essas comunidades rurais.

Os recursos naturais da região do Seridó Potiguar são explorados de forma contínua, com destaque para o município de Parelhas. Ter um corpo hídrico à disposição de populações que o utilizam para a sua subsistência exige novas posturas com relação à conservação e práticas de uso sustentável.

A partir do conhecimento da realidade local é possível fomentar medidas para subsidiar as populações residentes, possibilitando a estas utilizar de forma sustentável os recursos naturais disponíveis. Estudos nessa linha investigativa devem ser desenvolvidos para despertar o interesse de conservação dos recursos naturais locais disponíveis e para promover a participação comunitária, melhorando assim a qualidade ambiental e de vida da população rural residente.

\section{REFERÊNCIAS}

COSGROVE, D. (1998). A geografia está em toda parte: cultura e simbolismo nas paisagens humanas. In: ROSENDAHL, Z.; CORRÊA, R. L. (Org.). Paisagem, tempo e cultura. (Cap. 5, pp. 98-99). Rio de Janeiro: Ed. UERJ.

GIL, A. C. (2002). Como Elaborar Projetos de Pesquisa (4 ed.). São Paulo: Atlas.

HERCULANO S. et al. (Org.). (2000). A qualidade de vida e seus indicadores. Recuperado em 05 dezembro, 2011, de http://www.ivt-rj.net/ivt/bibli/Herculano.pdf

INSTITUTO BRASILEIRO DE GEOGRAFIA E ESTATÍSTICA - IBGE. (2010). Síntese de Indicadores Sociais 2010. Recuperado em 03 dezembro, 2011, de http://www.ibge.gov. $\mathrm{br} /$ home/estatistica/populacao/condicaodevida/indicadoresminimos/sinteseindicadoressociais20 11/SIS_2010.pdf 
. (2010). Cidades. Parelhas. Recuperado em 30 novembro, 2011, de http://www.ibge.gov.br/cidadesat/topwindow.htm?1

BRASIL. (2005). Ministério do Meio Ambiente. Secretaria de Recursos Hídricos. Panorama da desertificação no estado do Rio Grande do Norte. Recuperado 20 maio, 2011, de http://www.mp.go.gov.br/portalweb/hp/9/docs/monografia_mma_panorama_da_desertificacao_no_rio_grande_do_norte.pdf.

MAIA, G. N. (2004). Caatinga: árvores e arbustos e suas utilidades. São Paulo: D \& Z computação gráfica e Editora.

MORAIS, I. R. D. (2004). Seridó norte-rio-grandense: uma geografia da resistência. Caicó: Ed. Autor. NUNES, E. (2006). Geografia Física do Rio Grande do Norte. Natal: Imagem Gráfica.

RODRIGUEZ, J. M. M.; SILVA, E. V. (2002). A classificação das paisagens a partir de uma visão Geossistêmica. Revista Mercator. Ano 01, no 01, p. 96 - 112.

RODRIGUEZ, J. M. M.; SILVA, E. V.; CAVALCANTI, A. P, B. (2007). Geoecologia das paisagens: uma visão geossistêmica da análise ambiental. (2 ed.). Fortaleza: Editora UFC.

SANTOS, José Evaristo dos. (Orgs.) et al. (2004). Faces da Polissemia da Paisagem: ecologia, planejamento e percepção. São Carlos: RiMa.

SANTOS, M. (1997). Metamorfoses do espaço habitado. (5 ed.), São Paulo: Hucitec.

SOARES, F. M. (2002). Paisagem e paisagens: uso e ocupação da terra na bacia do rio Curu/CE. Revista Mercator. Ano 1, no 02. Recuperado em Disponível 19 julho, 2012, de http://www.mercator.ufc.br/index.php/mercator/article/viewFile/185/151

TUAN, Yi-fu. (1980). Topofilia- Um estudo da percepção, atitudes e valores do meio ambiente. São Paulo: Difel. 